\title{
Refugees or Victims of Human Trafficking? The case of migrant domestic workers in Hong Kong
}

\author{
Jade Anderson and Annie Li
}

\section{Abstract}

China is party to the 1951 Refugee Convention and the 2000 UN Trafficking Protocol, but has not extended coverage of either of the treaties to the Hong Kong Special Administrative Region of China (Hong Kong). Hong Kong does however offer non-refoulement protection on the basis of risks of torture or persecution. Further, Hong Kong legislation defines human trafficking, albeit only in terms of cross-border sex work. Victim identification also remains inadequate. The limited extant protection systems for refugees and victims of human trafficking operate separately and assume that such people are distinct with respect to their experiences and needs. These practices are often mirrored in the approaches of NGOs working in the city. Based on research undertaken by Justice Centre Hong Kong, this paper argues instead that boundaries between the two categories are blurry. The paper focuses on migrant domestic workers who may have claims to asylum and may be at the same time victims of human trafficking. It explores some of the implications for NGOs trying to secure better protections for such groups in Hong Kong. The paper concludes that siloing the refugee and the human trafficking frameworks creates a protection gap, particularly for people who enter Hong Kong as migrant domestic workers and cannot return home because they face a risk of persecution or torture.

Keywords: human trafficking, migration, refugee, migrant domestic worker, Hong Kong, non-refoulement, refugee status determination, Unified Screening Mechanism

Please cite this article as: J Anderson and A Li, 'Refugees or Victims of Human Trafficking? The case of migrant domestic workers in Hong Kong', Anti-Trafficking Review, issue 11, 2018, pp. 52-68, www.antitraffickingreview.org

This is an open-access article distributed under the terms of the Creative Commons Attribution License (CC-BY). Under the CC-BY license, the public is free to share, adapt, and make commercial use of the work. Users must always give proper attribution to the authors and the Anti-Trafficking Review. 


\section{Introduction}

Hong Kong is rarely considered in the context of contemporary concerns with refugee flows or human trafficking. Where protection systems for refugees and victims of human trafficking exist in Hong Kong, they operate separately and assume that these are distinct categories of people with different experiences and needs. Such distinctions are also reflected in the practices of many nongovernment organisations (NGOs), which assist refugees or victims of human trafficking (mainly among migrant domestic workers or sex workers) but rarely consider the potential overlaps.

This was also true of Justice Centre Hong Kong (Justice Centre), a local NGO that provides, inter alia, legal and psychosocial support to asylum seekers and refugees. Acknowledging that there may be various intersections between refugees and victims of human trafficking, Justice Centre undertook a small research project to explore indications of human trafficking amongst its clients. The analysis uncovered multiple indicators across a sample of client files and highlighted different points at which persecution/torture and human trafficking experiences possibly overlap. In examining the blurred boundaries between these categories, particular attention was paid to migrant domestic workers (MDWs), whose experiences are typically considered through the lens of human trafficking but generally not in the context of refugee claims. ${ }^{1}$

This paper, by the authors of the report on the above project, is both a discussion of Justice Centre's research and a reflection on its implications for the NGOs working on human trafficking and refugee issues in Hong Kong. We begin with an overview of the Hong Kong context, briefly describing how the protection systems for refugees and victims of human trafficking operate. We then go on to introduce the methodology and findings of the Justice Centre research, followed by an outline of the existing literature on MDWs in Hong Kong-as migrant workers, victims of human trafficking, as well as asylum seekers and refugees. Next, we explore two case studies from the

See: Justice Centre Hong Kong, Coming Clean: The prevalence of forced labour and buman trafficking for the purpose of forced labour amongst migrant domestic workers in Hong Kong, Hong Kong, 2016, available at: http://www.justicecentre.org.hk/ framework/uploads/2016/03/Coming-Clean-The-prevalence-of-forced-labourand-human-trafficking-for-the-purpose-of-forced-labour-amongst-migrantdomestic-workers-in-Hong-Kong.pdf. 
Justice Centre research, both of women who entered Hong Kong as MDWs and subsequently applied for non-refoulement protection, highlighting some of the ways in which asylum/refugee and human trafficking experiences may intersect. Finally, we use these case studies to consider the implications for NGOs and protection systems in Hong Kong.

\section{The Hong Kong Context}

Hong Kong has a population of approximately 7.4 million people and one of the most liberal visa regimes in the world in terms of ease of entry. ${ }^{2}$ The territory houses a significant number of people considered to be non-residents. Amongst them are some 370,000 MDWs, coming through a formal temporary labour migration programme and constituting 8.9 per cent of the labour force. ${ }^{3}$ There are a number of regulations in place for MDWs: a statutory minimum wage (which is lower than the minimum wage for non-MDWs), ${ }^{4}$ minimum weekly rest hours, paid leave, paid statutory public holidays, paid return trips to their home country, free health care, ${ }^{5}$ parental leave and

2 For example, over 170 nationalities may enter Hong Kong for business or pleasure visits visa-free for a stay ranging from 7 to 180 days. See: Immigration Department, Hong Kong Government, Annual Report 2016, chapter 2, retrieved 25 June 2018, https://www.immd.gov.hk/publications/a_report_2016/en/ ch02.html\#c2.

3 Hong Kong Government, Action Plan to Tackle Trafficking in Persons and to Enhance Protection of Foreign Domestic Helpers in Hong Kong, March 2018, available at: http: / / www.sb.gov.hk/eng/special/pdfs / Action \%20 Plan \%20 to\% 20 Tackle\%20TIP\%20and\%20to\%20Protection\%20FDHs.pdf; Census and Statistics Department, Hong Kong, Hong Kong Annual Digest of Statistics 2017 Edition), retrieved 25 June 2018, https://www.statistics.gov.hk/pub/ B10100032017AN17B0100.pdf.

4 Section 7(3), Minimum Wage Ordinance, Cap 608, available at: https:// www.elegislation.gov.hk/hk/cap608, retrieved 3 May 2018; Hong Kong Government, Hiring Domestic Helpers, available at: https://www.gov.hk/en/ residents/employment/recruitment/foreigndomestichelper.htm.

5 Immigration Department, Hong Kong, Employment Contract for a Domestic Helper Recruited from Outside Hong Kong - English Version, available at: https:// www.immd.gov.hk/eng/forms/forms/id407.html; Section 17, Employment Ordinance, Cap 57, available at: https://www.elegislation.gov.hk/hk/cap57. 
protection, a standard employment contract (two years) ${ }^{6}$ as well as procedures for employment agencies. ${ }^{7}$ Regulations also require MDWs to live in the household of their employer and prevent them from changing employers except under specific, limited circumstances. If a contract finishes or is terminated, they must leave Hong Kong within fourteen days. ${ }^{8}$

There are few protection mechanisms for non-residents in the city. While China is a state party to the Convention relating to the Status of Refugees (1951 Refugee Convention), the treaty has not been extended to cover Hong Kong. Until 2014, the United Nations High Commissioner for Refugees Sub-Office in Hong Kong undertook refugee status determination (RSD) for people claiming protection from persecution. The Hong Kong Government consistently justifies the non-application of the 1951 Refugee Convention on the grounds that they need to maintain immigration control and protect the local labour force. ${ }^{9}$ In the past, a different system applied to victims of torture. The Convention against Torture and Other Cruel, Inhuman or Degrading Treatment or Punishment was extended to Hong Kong in $1992^{10}$ and since then, judicial review has necessitated that the Hong Kong Government implement an administrative torture screening mechanism. ${ }^{11}$

- Immigration Department, Hong Kong, Employment Contract for a Domestic Helper Recruited from Outside Hong Kong - English Version; Section 12, Employment Ordinance, Cap 57.

7 Labour Department, Hong Kong, Code of Practice for Employment Agencies, February 2018, available at: https://www.eaa.labour.gov.hk/_res/pdf/CoP_Eng.pdf.

8 Immigration Department, Hong Kong, Current Limit of Stay, available at: https:/ /www.gov.hk/en/residents/immigration/nonpermanent/limitofstay.htm

9 Comment made by Billy Woo, Principal Assistant Secretary, Security Bureau, Hong Kong in the meeting of the Panel on Security, Legislative Council of Hong Kong on 30 April 2018, webcast available at: https:// webcast.legco.gov.hk/public/zh-hk/SearchResult?MeetingID=M18040019.

10 Legislative Council Secretariat, Review of the Torture Claim Screening Mechanism, Background brief prepared for the Panel on Security for the special meeting on 29 September 2009, 23 September 2009, available at: http://www.legco.gov.hk/ yr08-09/english/panels/se/papers/se0929cb2-2514-2-e.pdf.

11 Sakthevel Prabakar v Secretary for Security [2004] 7 HKCFAR 187, available at: http://www.hklii.hk/cgi-bin/sinodisp/eng/hk/cases/hkcfa/2004/ 43. html? stem $=$ \&synonyms $=$ \&query $=$ title $($ Sakthevel $\% 20$ Prabakar $\% 20$ and $\% 20$ Secretary $\% 20$ for $\% 20$ Security) $\% 20$ OR $\% 20$ ncotherjcitationtitles(Sakthevel $\% 20$ Prabakar $\% 20$ and $\% 20$ Secretary $\% 20$ for $\% 20$ Security) 
In March 2014, the Hong Kong Government began operating the Unified Screening Mechanism (USM), integrating the systems for the determination of torture and persecution claims, and assumed responsibility for assessing all claims made for protection within the territory. ${ }^{12}$ Today there are approximately 10,000 people seeking protection in the city from around seventy different countries of origin. ${ }^{13}$ However, access to protection remains limited. Since the commencement of the USM, Hong Kong has validated only 111 claims ${ }^{14}$ which equals a substantiation rate of about 0.8 per cent ${ }^{15}$ compared to rates of 25 per cent to 62 per cent in other developed jurisdictions. ${ }^{16}$ Moreover, whereas in other countries that undertake individualised RSD, successful applications result in lawful residence (permanent or temporary) with associated rights, successful applications in Hong Kong mean only that

12 UNHCR, 'Sub-office Hong Kong', available at: http://www.unhcr.org/hk/ en/2660-usm-faq-2.html.

13 Immigration Department, Hong Kong, 'Enforcement', available at: http:// www.immd.gov.hk/eng/facts/enforcement.html; Immigration Department, Hong Kong, Response to a data request titled 'Non-refoulement claimants whose claims have been finally determined, Mar 2018', 20 June 2018, available at: https://accessinfo.hk/en/request/non_refoulement_claimants_whose\# outgoing-451; Immigration Department, 'Breakdown of nationality of nonrefoulement claimants', Response to a data request, 12 July 2017, available at: https://accessinfo.hk/en/request/breakdown_of_nationality_of_non.

${ }_{14}$ Immigration Department, Hong Kong Government, 'Enforcement'; Security Bureau, Hong Kong, Response to a data request titled 'Non-refoulement claims substantiated/allowed at first instance and appeal', 20 October 2017, available at: https://accessinfo.hk/en/request/non_refoulement_claims_substanti; Hong Kong Government, 'LCQ4: Torture claims', press release, 7 May 2014, available at: http://www.info.gov.hk/gia/general/201405/07/P201405070624.htm

15 Ibid.

16 For example, the substantiation rates in the United Kingdom, Germany and Canada are 28\%, 25\% and 62\% respectively. See: Asylum Tables, volume one on Home Office, United Kingdom, 'How many people do we grant asylum or protection to?', 21 March 2018, available at: https://www.gov.uk/government/ publications/immigration-statistics-october-to-december-2017/how-manypeople-do-we-grant-asylum-or-protection-to; United Nations High Commissioner for Refugees (UNHCR), 'Country Update: Germany | Q1 2018', 13 November 2017, available at: http://www.unhcr.org/dach/wp-content/ uploads/sites/27/2018/03/Factsheet_Germany_O1_2018.pdf; UNHCR, 'Population Statistics', http://popstats.unhcr.org/en/asylum_seekers. 
people will not be returned to their countries of origin (non-refoulement). They are not given any form of lawful residence and can only apply for sixmonth permits to work, granted at the discretion of the Director of Immigration. ${ }^{17}$

The situation with human trafficking is equally troubling. Although China is a signatory to the Protocol to Prevent, Suppress and Punish Trafficking in Persons Especially Women and Children, Supplementing the United Nations Convention against Transnational Organized Crime, 2000 (UN Trafficking Protocol), it has not been extended to cover Hong Kong. Currently, legislation defines human trafficking only in terms of transnational sex work ${ }^{18}$ without requiring any element of force, fraud, or coercion. ${ }^{19}$ In 2017, nine victims of human trafficking were identified and another three were identified in the first four months of $2018 .^{20}$ In contrast, Justice Centre's primary research estimated that the prevalence of human trafficking amongst MDWs in Hong Kong was approximately 2.4 per cent, or around 8,000 people. ${ }^{21}$ Despite moves to develop an action plan to tackle human trafficking that includes new guidelines and an enhanced mechanism for victim identification and referral, ${ }^{22}$ the government continues to assert that there is no sign that Hong Kong is being actively used as a destination or transit point for human trafficking, or that human trafficking is a widespread or prevalent problem in the city. ${ }^{23}$

To the extent that systems for protection from persecution or torture and for victims of human trafficking exist in Hong Kong, they operate separately, including in the work of NGOs. Refugees are typically imagined as those fleeing political persecution while human trafficking is largely considered to be

17 Section 37ZX, Immigration Ordinance, Cap. 115, available at: https:// www.elegislation.gov.hk/hk/cap115.

18 Section 129, Crimes Ordinance, Cap. 200, available at: https:// www.elegislation.gov.hk/hk/cap200. The Hong Kong legislation refers to 'prostitution'.

19 Ibid.

20 Heidy $\mathrm{Ng}$ (for Secretary for Security), Response to access to information request 'Human trafficking victims identified', 3 July 2018, available at: https:// ccessinfo.hk/en/request/human_trafficking_victims_identi\#incoming-773.

${ }^{21}$ Justice Centre Hong Kong, Coming Clean.

22 Hong Kong Government, Action Plan to Tackle Trafficking in Persons and to Enhance Protection of Foreign Domestic Helpers in Hong Kong.

23 Ibid. 
affecting MDWs and sex workers. ${ }^{24}$ Theoretically, when experiences of being trafficked amount to persecution or torture risks, these should be considered in the evaluation of non-refoulement claims, but the Hong Kong Government does not maintain data about the numbers of such cases. ${ }^{25}$

\section{Methodology}

In 2016, Justice Centre undertook research to explore what indicators of human trafficking might be present in its client files of asylum seekers and refugees. These files had previously only been considered in the context of persecution or torture claims. To begin with, we conducted a series of interviews with local and international experts, including NGO staff, for background information and to develop a framework for analysing client files. We also used these interviews to learn how NGOs responded to victims of human trafficking seeking non-refoulement protection.

Ultimately, the analysis framework consisted of indicators of the act, means, and purpose elements defined in the UN Trafficking Protocol. These were derived from Operational Indicators of Trafficking in Human Beings (2009) and Hard to See, Harder to Count (2012) published by the International Labour Organization, ${ }^{26}$ as well as Forced Marriage as a Form of Human Trafficking by the South Asian Women's Centre in 2014. ${ }^{27}$

${ }^{24}$ For example, Amnesty International published a report in 2013 arguing that the recruitment and working conditions for many MDWs from Indonesia were tantamount to human trafficking. Justice Centre's own research only examined trafficking amongst MDWs. Recent press stories highlight the experiences of women entering Hong Kong believing they would be employed in domestic work but were forced into sex work to pay the costs of mounting debts; see: S Yu 'Forced Smiles Mask Pain of Hong Kong's Trafficked Bar Girls', Thomson Reuters Foundation, 28 February 2017, available at: http://news.trust.org/item/ 20170301010631-hi4fe/.

25 Immigration Department, 'Non-refoulement claims of victims of human trafficking', Response to a data request, 8 May 2017, available at: https:// accessinfo.hk/en/request/non_refoulement_claims_of_victim\#incoming-466

26 International Labour Organization, Operational Indicators of Trafficking in Human Beings, ILO, Geneva, 2009; International Labour Organization, Hard to See, Harder to Count, ILO, Geneva, 2012.

27 South Asian Women's Centre, Forced Marriage as a Form of Human Trafficking, 2014, available at: http://www.sawc.org/wp-content/uploads/2015/04/ Forced-Marriage-as-a-Form-of-Human-Trafficking-Resource-Guide.pdf. 
Justice Centre had over 1,000 case files but to ensure findings were relevant to the current regime in Hong Kong, only clients who registered with Justice Centre after the USM was introduced were sampled (roughly half of the files). The cases considered for the sample also needed to contain at least one of the following to ensure sufficiency of information: (i) a Justice Centre assessment form, (ii) a testimony, (iii) an interview transcript provided by the Immigration Department, or (iv) a notice of determination of the Immigration Department or Torture Claims Appeal Board. Since the objective of the research was to study the protection needs of those who were using or had used the USM, we did not limit the included files to cases which had been substantiated. Instead, the sample also covered case files of rejected claims as well as some still in progress. Sampled cases thus illustrate accounts of persecution and/or torture, irrespective of whether these have been legally recognised as such. Finally, clients had to consent to their data being used for research purposes. Based on these criteria, we employed convenience sampling, choosing the first fifty case files that met our criteria in chronological order.

Capturing experiences prior to arrival in Hong Kong, eleven of the fifty files triggered at least one indicator of each of the act, means and purpose elements of human trafficking. ${ }^{28}$ None of the cases prompted each of the act, means and purpose elements for events that occurred in Hong Kong. Only four of the sampled files included any data about experiences of work in Hong Kong, which limited our ability to assess human trafficking indicators.

The case-file analysis was supplemented with client interviews if their file had triggered human trafficking indicators and they consented to a follow-up. Four clients agreed to participate. The interviews were semi-structured and covered a range of topics including the mode of arrival in Hong Kong; potential experiences of exploitation in the home country or in Hong Kong; and possible abuse of vulnerability by smugglers, agents or other third parties, which might not have been included in their case files.

There are a number of limitations to the study. Due to capacity constraints, we were only able to analyse fifty files and interview four clients. The research is thus exploratory only and far from exhaustive; hence, no definitive conclusions should be drawn.

28 The different elements were not necessarily related to the same experience or incident and significantly more investigation would be required to establish if the client had in fact been a victim of trafficking and whether these experiences triggered their flight to Hong Kong. 


\section{Migrant Domestic Workers as Victims of Human Trafficking or Refugees}

There is extensive literature on MDWs in Hong Kong, ${ }^{29}$ a comprehensive review of which is beyond the scope of this article. Still, it is helpful to outline some of the ways in which migrant domestic work, predominantly performed by women, is examined in the context of human trafficking and asylum. Studying migration and trafficking of Indonesian women, Rebecca Surtees argues that MDWs are vulnerable to human trafficking through the intersection of the recruitment process (which can involve deception about the nature and conditions of work, and the incurring of debts for the costs of recruitment) with the conditions of work once in employment. Surtees notes that 'there is great potential for problems amongst domestic workers given that they are isolated in employers' homes, unable to rely on others as either witnesses or sources of support and protection'. ${ }^{30}$ Due to isolation in individual households, they are vulnerable to exploitation and human trafficking.

Bridget Anderson argues that domestic work is qualitatively different from other forms of work due to the unequal power relations between the worker and the employer. ${ }^{31}$ She maintains that the migrant status of the MDW further compounds this inequality, noting that in places where they are tied to an employer by their immigration status (as in Hong Kong), they are legally dependent on their employer; and where they live-in (again as in Hong Kong), the employer literally controls all aspects of their life. This dependency reinforces the unequal power relationship between the MDW and the employer, creating fertile grounds for exploitation and abuse. ${ }^{32}$

29 See for example, G Chia, 'Focussing the Familiar? Locating the foreign domestic worker in postcolonial Hong Kong discourse', Cross-Sections, vol. viii, 2012, pp. 1-12; S Chiu, A Stranger in the House: Foreign domestic helpers in Hong Kong, Hong Kong Institute of Asia-Pacific Studies \& Chinese University of Hong Kong, 2005; V Wee and A Sim, 'Hong Kong as a Destination for Migrant Domestic Workers' in S Huang, BSA Yeoh and NA Rahman (eds.), Asian Women as Transnational Domestic Workers, Marshall Cavendish Academic, 2005, pp. 175209; N Yellan et al., "We Spend More Time with the Children than They Do

...": Education, care and the work of foreign domestic workers in Hong Kong', Globalisation, Societies and Education, vol.11, issue 4, 2013, pp. 443-458.

30 R Surtees, 'Female Migration and Trafficking in Women: The Indonesian context', Development, vol. 46, issue 3, 2003, p. 100.

31 B Anderson, Doing the Dirty Work? The global politics of domestic labour, Zed Books, London, 2000, p. 121.

32 Ibid, p. 177. 
Moreover, Nicole Constable argues that two immigration regulations in Hong Kong-the live-in requirement and the rule that MDWs have to leave within fourteen days of the completion or termination of contracts - make them particularly vulnerable and ensure that 'many prefer to put up with poor or illegal working conditions rather than suffer the financial hardship of pursuing legal action or returning home'. ${ }^{33}$ Thus, as Hans Ladegaard notes, notwithstanding legislation designed to protect MDWs rights in Hong Kong, many are exploited, assaulted and abused. ${ }^{34}$ He maintains that their work is not only devalued, but that the 'blatantly racist discourses' regarding MDWs are 'considered legitimate and natural'. ${ }^{35}$ These two factors combine to facilitate the abuse and exploitation of MDWs and at the same time allow the general public in Hong Kong to insist that stories of their abuse 'are untruthful or grossly exaggerated'. ${ }^{36}$ Ladegaard concludes that Hong Kong 'is a society that welcomes [MDWs] as workers but not as human beings. ${ }^{37}$

There is less research on MDWs and asylum. During his fieldwork with asylum seekers in Hong Kong, Francesco Vecchio noted that 'a number of domestic helpers were resorting to seeking asylum with the Immigration Department in order to prolong their stay in the territory'. ${ }^{38}$ Vecchio's concern is with the survival strategies of those seeking asylum in Hong Kong and, in particular, with the informal and illegal work undertaken by (mostly male) asylum seekers. He does not enter into a discussion of the 'genuineness' of the asylum claims of former MDWs, or of what might constitute a 'genuine' claim for asylum in such cases. Instead, he examines the connection between asylum and illegal work, noting that former MDWs sometimes continue in informal domestic work after they have submitted a claim for asylum. ${ }^{39}$ Vecchio remarks, however, that a number of his non-refugee research participants expressed concern that former MDWs and their asylum-seeking boyfriends were 'exploiting the system'. ${ }^{40}$ These respondents were alarmed that MDWs were 'shelter[ed] from deportation by claiming asylum' after becoming pregnant. ${ }^{41}$

33 N Constable, Maid to Order in Hong Kong: Stories of migrant workers, $2^{\text {nd }}$ ed., Cornell University Press, 2007, p. 212.

34 H J Ladegaard, The Discourse of Powerlessness and Repression: Life stories of domestic migrant workers in Hong Kong, Routledge, 2016, p. 3.

35 Ibid, p. 119.

36 Ibid, p. 142.

${ }^{37}$ Ibid, p. 119.

38 F Vecchio, Asylum Seeking and the Global City, Routledge, 2015, p. 178.

39 Ibid, p. 178-9.

40 Ibid, p. 145.

41 Ibid. 
Constable has also written about MDWs claiming asylum in Hong Kong. She examines asylum claims used as a strategy by those who become pregnant and try to secure a legal title to stay in the city. ${ }^{42}$ Constable does not focus on the specific nature of the claims former MDWs might make. However, she does analyse how their claims are perceived by NGO staff in comparison with the claims of 'political refugees', ${ }^{43}$ noting that there is an impression that 'real' refugees 'file claims immediately upon entering the country; and that they do not enter Hong Kong as a [...] domestic worker' before declaring their need for protection. ${ }^{44}$ To our knowledge, therefore, there has been little substantial investigation into the refugee-trafficking nexus in Hong Kong or where and how people who enter the territory as MDWs may face persecution and/or torture risks.

\section{Migrant Domestic Workers as Victims of Trafficking and Refugees?}

Of the four clients who consented to interviews for our research, two had entered Hong Kong as MDWs. As argued elsewhere, the categories of refugee and victim of human trafficking are 'not mutually exclusive [and such] experiences can best be understood along a continuum, with individuals occupying multiple "identities/statuses" at different stages of their lives'. ${ }^{45}$ This is demonstrated in the two Justice Centre case studies. ${ }^{46}$

Rose came from a very poor family in a rural part of Asia. Her parents had acquired large debts and, to repay the debts, Rose's father had forced her to marry his creditor, Aman. Rose, although still a child at the time of the marriage, had to work in the home and on the farm of Aman's family for 16 hours a day. She was given little food and was often hit, kicked and smacked by Aman and his relatives. Aman also frequently raped her and threatened to kill her, claiming she had been sold to him. Rose's parents attempted to mediate the situation and sought help from community leaders but their attempts

${ }^{42}$ N Constable, Born Out of Place: Migrant mothers and the politics of international labor, HKU Press, Hong Kong, 2014, p. 184.

43 Ibid.

44 Ibid, pp. 190-191.

45 A Brunovski and R Surtees, Vulnerability and Exploitation along the Balkan Route: Identifying victims of human trafficking in Serbia, Fafo, Oslo, 2017, p. 12.

46 All names have been changed to protect the clients' privacy and safety. 
were not successful. One of Rose's neighbours had worked in Hong Kong as a MDW and introduced a broker to Rose's parents. Rose's parents then borrowed money to pay the broker and the employment agency to arrange work for Rose in Hong Kong. Rose's story suggests that she was trafficked for forced marriage and labour while still a child. Still, her flight from this situation was not undertaken as a 'refugee' or a 'victim of human trafficking' but as a 'labour migrant'.

Before she travelled to Hong Kong, Rose stayed with the employment agency for several months for training. During this time, Aman could not find her and instead attacked her family. In her first contract in Hong Kong, Rose earned less than the minimum allowable wage and had to repay the employment agency training fees, keeping only about USD 100 every month. Neither she nor her parents could repay their original debt to Aman, and he continued to harass and attack her parents. Eventually, her employer terminated her contract after Aman called the house repeatedly to ask for money. Rose then worked for another four employers in Hong Kong. Starting from her second employment contract, she was paid the minimum allowable wage and could remit money home to repay her recruitment debt. Still, she was unable to repay her parents' original debt to Aman.

Rose worked for more than seven years in Hong Kong. After her last employment contract ended, she again found a new employer but he failed to prepare a contract for her in time. Rose requested that the Immigration Department extend her working visa in order to allow her to process the required documentation but the Department extended her visa for one day only. Rose was unable to submit the documents before the visa expired. Fearing that Aman would kill her because she would not be able to repay the money her parents owed him, she remained in Hong Kong, 'over-staying' and effectively becoming 'irregular'.

While in this 'irregular' state, Rose became pregnant, radically changing her needs and decreasing the viability of her status as an overstayer. In addition, it made Rose unemployable as a MDW. Even if the Immigration Department were to allow her to be eligible for an employment visa after overstaying, she would have to live with her employer. However, there are few employers who would be willing to host a MDW accompanied by an infant. With a son born out of marriage, Rose now had an additional fear about returning home- the fear of not being accepted by her family and community. Seeking the assistance of a local NGO, she learnt about the opportunity to make a non-refoulement claim. With neither flight nor work being feasible options, Rose found that her only chance of remaining in Hong Kong lay in invoking the non-refoulement 
principle. Her initial application for protection was rejected and she was appealing the decision at the time of the interview.

The complexities of an individual's experiences when compared with bureaucratic categories are also demonstrated by the case of Bibi. The murder of a family member brought her family into dispute with a politically influential figure. After contacting the police, Bibi suffered severe sexual abuse by public officials and faced death threats from the politically influential figure. Afraid for her life, she sought help from a family friend, Taylor, who suggested that she travel to Hong Kong to work as a MDW. Taylor organised everything for Bibi: her passport, visa, the employment contract, and her plane ticket. Bibi's mother took out a loan to cover the costs of travelling to Hong Kong.

Once in Hong Kong, Bibi found herself working for 21 hours a day with only a few hours off on Sundays. She had to repay Taylor while the employer underpaid her, leaving her with less than USD 50 a month. Even though she disliked the working conditions and was exhausted, Bibi was reluctant to quit. She did not think that she had fully repaid her recruitment debt; was worried that she did not have enough money to support herself in Hong Kong without a job; and was scared that she would be killed if she returned home. Before the two-year contract was finished, however, Bibi decided that she could not take it any longer and quit. With the assistance of a local NGO, she lodged a case against her employer with the Labour Tribunal to claim back her withheld wages. She was partially successful; the Labour Tribunal awarded her a small percentage of the wages owed to her and the money for a plane ticket home. Not knowing anything about her right to protection, Bibi did not tell the NGO or the Labour Tribunal that she feared returning home. For Bibi, what had happened to her at home was irrelevant to the Labour Tribunal process, and the NGO's goal was to enable her to use the available redress avenues for labour issues. From the moment Bibi terminated her employment contract and for the duration of her case in the Labour Tribunal, she was not legally allowed to work and relied on the assistance of NGOs.

However, Bibi was still too afraid to go home. When her visa expired, she decided to remain in Hong Kong. With the support of a friend and assistance from some churches, Bibi survived for a year in Hong Kong as an overstayer. She was eventually caught by the police and arrested. Placed in a detention centre, she was informed by the Immigration Department staff of the possibility to make a claim for non-refoulement protection as a victim of torture. Her initial claim was rejected as was her subsequent appeal/petition with the Torture Claims Appeal Board. She was challenging the Torture Claims Appeal Board decision by way of judicial review at the time of the interview. 


\section{NGO Responses to Migrant Domestic Workers Seeking Protection}

As noted in the literature review above, Rose and Bibi's initial status as migrant workers may well raise doubts about the 'genuineness' of their refugee claims. Constable argues that former MDWs who submit non-refoulement claims 'are often regarded with scepticism and criticism' by NGO staff. ${ }^{47}$ She notes that some staff at NGOs consider them 'less deserving', 'a time-consuming nuisance at best, or undeserving and immoral at worst, taking resources to which they are not entitled'. ${ }^{48}$ In this assessment, submitting applications for protection through the USM is only ever about prolonging their time in Hong Kong and securing some form of support. Whilst USM applications by MDWs might be understandable given their circumstances, they are not 'genuine' cases for protection. ${ }^{49}$

In our interviews with NGO staff, one respondent initially expressed concerns that non-refoulement claims made by potential victims of human trafficking would slow the government's processing of non-refoulement claims overall, making it even harder for refugees to access the limited protection available. ${ }^{50}$ Given the low substantiation rate and the time it can take the government to evaluate claims, concerns about delays are not unwarranted, but they are also influenced by ideas about what constitutes a 'genuine' refugee and seem consistent with Constable's conclusion that some NGO staff do not believe MDWs could need protection in the same way as refugees.

If, however, MDWs have legitimate claims to refugee protection as well as to being victims of human trafficking, what then are the implications for them and for NGOs? As asked by one NGO employee, 'What's in it for the individual MDW?'51 While refugees are afforded extremely limited humanitarian assistance, they are given protection from refoulement and can

47 Constable, 2014, p. 16.

48 Ibid.

49 Ibid, pp. 16-17.

50 Interview on 9 November 2016.

${ }_{51}$ Remark made in an NGO roundtable on Justice Centre Hong Kong's research exploring the nexus between refugees and human trafficking on 25 May 2017 in Hong Kong. 
subsequently apply for resettlement in a third country through the UNHCR. ${ }^{52}$ Hong Kong's substantiation rate is extremely low, the process can take years, and even if a claim is substantiated, the resettlement process is time-consuming and with its own limited chances of success. ${ }^{53}$ For the duration of this process, however, refugees and asylum seekers receive some form of financial and inkind assistance.

At the same time, very few people have been officially identified as victims of human trafficking and it is unclear how the government's new action plan will be implemented in practice and improve victim protection. ${ }^{54} \mathrm{NGOs}$ and international organisations undertake their own screening processes and provide assistance to those whose claims they recognise. In some circumstances, this extends to support to return home, ${ }^{55}$ but without official recognition, this support can never translate into protection from refoulement, even where needed.

Many NGOs in Hong Kong (including Justice Centre) would argue that neither of the two categories and their associated forms of protection is adequate. However, exploring where and how they overlap is essential to securing as

52 Following substantiation of a non-refoulement claim made on persecution risk, UNHCR assists the claimant to be resettled to a third country because the claimant is never awarded residence in Hong Kong.

53 As of 2017, only four non-refoulement claimants have been resettled to a third country or have applications to resettle accepted by a third country since the start of the USM in 2014, according to the Immigration Department. See the webcast of the meeting of the Subcommittee to Follow Up Issues Relating to the Unified Screening Mechanism for Non-refoulement Claims of the Legislative Council of Hong Kong on 27 March 2018, available at: https:// www.legco.gov.hk/yr16-17/english/hc/sub_com/hs54/agenda/ hs5420180327.htm.

${ }^{54}$ For more information about the Action Plan to Tackle Trafficking in Persons, see: Justice Centre Hong Kong, 'Submission to the Panel on Security of the Legislative Council on the Administration's Action Plan to Tackle Trafficking in Persons and to Enhance Protection of Foreign Domestic Helpers in Hong Kong and the Proposed Members' Bill Entitled "Modern Slavery Bill” to Criminalize All Forms of Human Trafficking in Hong Kong', available at: http:// www.justicecentre.org.hk/framework/uploads/2014/03/Justice-Centre-HongKong-Submission-to-Panel-on-Security-human-trafficking-20180605.pdf.

55 The International Organization for Migration (IOM) assists victims of human trafficking with voluntary return and reintegration and resettlement. See: IOM, 'China', retrieved 16 June 2017, https://www.iom.int/countries/china\#rmmoe. 
much protection as possible to vulnerable people outside their country of origin. Individuals who have experienced trafficking and who are also at risk of persecution or torture at home need protection, at least in the form of non-refoulement. The protection offered to refugees in Hong Kong is inadequate, but it is the first step towards safety. In the case of MDWs, access to this protection requires that the Hong Kong Government and NGOs recognise the possibility that they can be refugees as well as victims of human trafficking. It also requires that NGO staff screen for persecution/torture risks among human trafficking victims.

\section{Conclusion}

Didier Fassin contends that refugee status determination is a constant project of interpretation. ${ }^{56}$ Decision makers create 'genuine' refugees through their interpretation and evaluation of the claims made by individuals. The same can be argued for victims of human trafficking. Of course, these interpretative projects are not limited to official decision makers. Julia Dahlvik notes that in the process of determining refugee status, 'asylum claimants, caseworkers, and experts compete over who defines what constitutes a fact, what is worth being documented, and what is credible — and what is not ${ }^{3} \cdot{ }^{57}$ Moreover, as Dahlvik comments, 'power is unequally distributed, usually to the disadvantage of the asylum claimant'. ${ }^{58}$ While they may make claims to a refugee or a victim of human trafficking status, and while they potentially participate in the process through the provision of evidence, MDWs do not control how their story is interpreted, whether it is considered truthful or important.

NGO staff play an important role in the identification of different forms of vulnerability amongst MDWs, and in deciding which forms of protection to try to access in Hong Kong. If we are to fight for better assistance for vulnerable migrants in Hong Kong, then NGOs need to be able to push both interpretive projects, and to reflect on the complex experiences of those trying to access protection.

56 D Fassin, 'The Precarious Truth of Asylum', Public Culture, vol. 25, issue 1, 2013, pp. 39-63, p. 40.

${ }^{57}$ J Dahlvik, 'Asylum as Construction Work: Theorizing administrative practices', Migration Studies, vol. 5, issue 3, 2017, pp. 369-388, p 381.

58 Ibid. 
Jade Anderson is the Head of Research at Justice Centre Hong Kong. She has been working in human rights-based development since 2002 for local and international NGOs in Afghanistan, Pakistan, India and South Africa and with the UNHCR in Australia. She holds a Master's degree in Applied Anthropology and Participatory Development and a Master's in International Development. She is the co-author of the Justice Centre Hong Kong report Coming Clean. Email: jade@justicecentre.org.hk

Annie Li is the Research and Policy Officer at Justice Centre Hong Kong. In this capacity, she conducts research and advocates for laws and policies to protect and promote the rights of asylum seekers, refugees, victims of torture, forced labour and human trafficking, and other people seeking protection. Previously, she has worked at Hong Kong civil society organisations AIDS Concern and Hong Kong Unison in communications and advocacy on healthcare issues, LGBTI rights and racial equality. She holds a Bachelor of Laws degree and a Bachelor of Social Sciences (Government and Laws) degree from the University of Hong Kong. Email: annie@justicecentre.org.hk. 